\title{
Impact of the Climatic Change on the Seasonal Movement of the Gujjar and Bakarwals: Community Perceptions
}

\author{
Dr.Mohd. Tufail \\ Post Doctoral Fellow, Centre for the Study of Regional Development,School of Social Sciences, Jawaharlal \\ Nehru University, New Delhi.
}

\begin{abstract}
Climatic change is an absolute reality which is experienced by the Gujjar and Bakarwal community of Kashmir which is affected from the climatic change with respect to its seasonal movement cycle with the livestocks which is disturbed from the last few years. Their economy is totally based on the livestock which is shattered by the droughts, unseasonal snowfall and other climate related problems in the region. The problem of climate related displacement in Kashmir poses major risks to societal sustainability of the Gujjar and Bakarwals. The seasonal movement of the Gujjar and Bakarwals is purely seasonal in character. They keep moving all round the year with respect to the availability of the pastures for their livestocks. But from the past few years their cycle of seasonal movement is disturbed due to the droughts in the Kashmir Valley, unseasonal snowfall in the summer months.
\end{abstract}

Keywords: Gujjars and Bakarwals, Climatic Change, Seasonal Movement

\section{Introduction}

Gujjar and Bakarwals face a number of problems. The data presented in the below tables and diagrams shows the nature of problems faced by nomadic Gujjars and Bakarwals. The major problem reported is that of related to nature, medical facilities, marketing of their products and harassment by the police-military forces and militants.

One of the major problems is the impact of Climate change on transhumance practice of the Gujjars and Bakarwals. Climatic change is an absolute reality which is experienced by the Gujjar and Bakarwal community of Jammu and Kashmir which is affected from the climatic change with respect to its seasonal movement cycle. In this section at attempt has been made to analyse the impact of the changing climatic conditions on the Transhumance practice of the Gujjars and Bakarwals. Certain questions were asked to the respondents about their perception about the changing climatic conditions and its impact on their transhumance practice.

So by keeping in mind the Bakarwal tribe is chosen as part of the study. An attempt has been made to access the impact of the climatic change on the seasonal movement of the tribe and their livelihoods. The survey sites were chosen based on their potential to contribute to a better understanding of the impact of climate change on the livelihoods of the Bakarwals. 400 households are surveyed both in the winter pastures (in plains) and summer pastures (in higher reaches of the Kashmir) to know the impacts of the climatic change.

The Cycle of Seasonal Movement during the Normal Period is somewhat different from of these years. The pastoral economy of the Bakarwals mainly depends on the utilization of the extensive pastures. The availability of the pastures is markedly seasonal in character while snow covers the mountains in the north; pastures are available throughout the winter in the south. But late April the winter pastures are exhausted, while the melting of the snow in the north give way to green and lush pastures. Thus both the winter and summer zones are characterized by the availability of pastures in a defined part of the year. This leads to oscillation between summer and winter zones while the coming of summer is signalled by the drying up of the pastures in the south, they take the animals during this time to higher or cooler altitudes in the north.

Bakarwals cross through nine major mountain passes of PirPanjal to reach their summer areas. The main mountain passes are Nandangali and PirkiGali which holds more than seventy percent of the seasonal movement of the Bakarwals. Mainly they cross these passes by the end of April. But the story is different during the last few years according to some respondents. For most of the Bakarwals climatic change is a reality. During these years the unusual warm march has forced the Bakarwals to cross these passes one month before the schedule time. Due to sudden change in temperature it leads to impact on the newborn livestock in their winter pastures which is a major source of the economy for the community because March is the time when sheep and goat, give birth. So a new and urgent problem of water and fodder shortage has forced the Bakarwals to move early towards summer pastures according to survey. To migrate too early Bakarwals are forced in the pastures which do not offer good grazing due to immediate melting of snow. Due to early arrival in their summer pastures, temperature is too much low it affected their livestock population. So a new problem arises for them due to comparatively higher temperature of March and no rainfall, forced them for the early movement which 
effected their production.

The effects of climate change on the seasonal movement practice of the Bakarwals in Kashmir pose difficult policy challenges. The arid nature of the climate together with the poverty levels faced by those people living in the mountains mean that the increasing temperatures, the intensifying rains and the increased frequency of extreme weather events leads to cause of concern for the livelihoods of the Bakarwals.

The Cycle of Seasonal Movement during the Normal Period is somewhat different from of these years. The pastoral economy of the Gujjar and Bakarwals mainly depends on the utilization of the extensive pastures. The availability of the pastures is markedly seasonal in character while snow covers the mountains in the north; pastures are available throughout the winter in the south. But late April the winter pastures are exhausted, while the melting of the snow in the north give way to green and lush pastures. Thus both the winter and summer zones are characterized by the availability of pastures in a defined part of the year. This leads to oscillation between summer and winter zones while the coming of summer is signalled by the drying up of the pastures in the south, they take the animals during this time to higher or cooler altitudes in the north.

Mainly Gujjars and Bakarwals cross through the passes by the end of April. But the story is different during the last few years according to some respondents. For most of the Gujjar and Bakarwals climatic change is a reality. During these years the unusual warm march has forced the Gujjar and Bakarwals to cross these passes one month before the schedule time. Due to sudden change in temperature it leads to impact on the newborn livestock in their winter pastures which is a major source of the economy for the community because March is the time when sheep and goat, give birth. So a new and urgent problem of water and fodder shortage has forced the Gujjar and Bakarwals to move early towards summer pastures according to survey. To migrate too early Gujjar and Bakarwals are forced in the pastures which do not offer good grazing due to immediate melting of snow. Due to early arrival in their summer pastures, temperature is too much low it effected their livestock population. So a new problem arises for them due to comparatively higher temperature of March and no rainfall, forced them for the early movement which effected their production. Mortality rate among the herds has been increased from the last few years. Increased temperature in the March April effects the animals, because this is the breeding season for the animals.

In (2009) the Gujjar and Bakarwals tribe had started their seasonal migration towards upper reaches by one month ahead of their routine schedule, due to unusual rise in daily temperature in Jammu and Kashmir State but later the season changed and they trapped in mountainous range of Himalaya and subsequently unseasonal snowfall which was continue for two weeks killed more than 50 humans and lakhs of the animals were being perished, Javaid Rahi.

What they say (interview of a shepherd): "We are all singing the same song," said MukhtarChechi, a shepherd from the BajranKafila. "We are trying to tell the rest of the world, 'look, we are seeing these things, and you are not doing anything about it.' If the animals die, we die. If the pastures dried we will be no more. If the river dies, we are gone. Gujjar and BakarwalTribe is at the forefront of climate change, in respect to impacts, Chechi said"

The impacts of Climate Change, as predicted by various quires, includes increasing temperatures, changing precipitation patterns, increasing severity of drought periods, more frequent extreme weather events, earlier snow melt in the mountains and unseasonal snowfall during the summer months.

\section{Community Perceptions about the Climate Change}

Concern is growing among community members over changes in earlier weather condition observed in the transhumance areas. Comparisons made on the indigenous knowledge on weather conditions in the past and present, show there is a consensus among transhumance communities that change has occurred. The communities visited were unanimous about changes in temperature and rainfall levels.

\begin{tabular}{|l|l|l|}
\multicolumn{4}{|c}{ Climate Changes and Associated Community Perceptions } \\
\hline \multicolumn{1}{|c|}{ Climatic factors } & \multicolumn{1}{c|}{ Changes } & \multicolumn{1}{c|}{ Community perceptions } \\
\hline Rain & $\begin{array}{l}\text { Decreased over the } \\
\text { past } 20 \text { years }\end{array}$ & $\begin{array}{l}\text { The transhumance calendars have shifted and rainy seasons are no } \\
\text { predictable, Less water availability for humans and livestock; force } \\
\text { the earlier movement to summer pasture areas. }\end{array}$ \\
\hline Temperature & $\begin{array}{l}\text { Increased over the } \\
\text { past twenty years }\end{array}$ & $\begin{array}{l}\text { Progressive increase over the past 20 years, noted drying up of the } \\
\text { water sources due to high temperature in and around the Jammu } \\
\text { hills (winter pasture areas). }\end{array}$ \\
\hline Unseasonal snowfall & $\begin{array}{l}\text { Increased over the last } \\
20 \text { years }\end{array}$ & $\begin{array}{l}\text { Like In May 2009 it happened which continues for 15 days, first } \\
\text { time in the summer months, killed 50 community members and } \\
\text { lakhs of the animals. }\end{array}$ \\
\hline Droughts & $\begin{array}{l}\text { More severe over the } \\
\text { past 20 years }\end{array}$ & $\begin{array}{l}\text { Increase in the summer pastures, drying up of the pastures, no } \\
\text { rainfall in the winter areas too. }\end{array}$ \\
\hline Source: Field Work,(2011)
\end{tabular}


However, some of them believe that these changes are due to "God punishment" for the "sins and transgressions" of humankind. Generally, climate change is already happening with its impacts being felt by most of the people in the state, particularly transhumance communities, who are more vulnerable to its effect as they rely on livestock production that is highly weather sensitive.

Change in rainfall has an impact on water sources and availability, as well as livestock production. This has led overall to increased vulnerability in food and water scarcity, with direct impacts on the livestock which force the community to move early to the summer pastures in the higher reaches of the Kashmir valley.

Above table shows that changes in temperature, rainfall, unseasonal snowfall, drought in the Gujjar and Bakarwal areas. The researcher asked respondents to discuss observed changes in the major climatic factors relevant to their landscape and livelihoods, as well as any overall changes to climatic trends over a period of time. The overall community perception in the Jammu and Kashmir was that there has been change in the climate. It is likely that because inhabitants of this area are already used to extreme Climatic changes including years of no rain, severe droughts in the summer pastures and winter pastures as well, unseasonal snowfall like in the year 2009.

Most of the elder members of the community consider this phenomenon as a problem generated due to the increasing sins committed by the people. They call it a Kalyug, which means that people have become too greedy, have lost faith in God and have moved towards material gains. They have also stopped worshipping.

\section{Unseasonal Snowfall, Hailstorm}

\section{Impacts of the Climate Change on the Community}

From the below table 6.2 it can be concluded that climatic change is a reality for the community, as here we can see that more than half of the livestock were perished in the unseasonal snowfall in the year of 2009. More than 50 community members were died due to unseasonal snowfall in 2009 which continues for 15 days. A survey is being conducted in the Pirkimarg summer pasture of the Jammu and Kashmir. Many families are surveyed to know the total number of animals in the last seven years. Lentho a transhumant of the same pasture land, he has 154 cattles in 2006, in 2007 it increased to 162 but in the 2009 it comes down to only 55 so more than 70 percent of the cattles are died due to untimely snowfall. According to many of the community members this was the first time they have seen snowfall in the month of may 2009. According to the elder members of the community this unseasonal snowfall happened first time in the summer months.

Nearly 1 lakh livestock are died in this natural disaster. More than 50 members of the community are died due to the extreme weather. Unseasonal snowfall and heavy rain have put at high risk the lives of over three lakh to five lakh nomadic Gujjars and Bakarwals along with livestock in 2009 as they got trapped at different points in the mountain ranges. They got trapped at upper reaches of PirPanchal, Doda, Anantnag, Kulgam, Zojiala pass JamiaGali, Pir Ki Marg, Chhapran, Upper Banihal, Wadwan, Trichhal, Mughal Road, Gurez, Macheil sector due to unseasonal snowfall. According to many of the respondents this is happened due to the climatic change. The Tribal Research and Cultural Foundation (TRCF) said over three lakh to five lakh nomadic Gujjars and Bakarwals are trapped at mountain ranges in 2009 while they were in search for pastures for livestock during their seasonal migration since April.

Transhumance practice is in crisis across Jammu and Kashmir, whether it is due to the hostility from the last two decades or due to the climatic change. In the scorching midday heat, less than 100 kilometres away from the Jammu city in Nowshera region of the state, there is a chorus of voices singing as water is hauled in buckets out of a mud hole and passed along the line to fill up a trough for livestock. The majority of community members in the Jammu and Kashmir state are transhumants, who move with their livestock in search of good pasture.

Family wise livestock Population of Pir Ki Marg Pasture and the impact of

Unseasonal Snowfall in the year 2009

\begin{tabular}{|l|l|l|l|l|l|l|l|}
\hline \multirow{2}{*}{ Name of the family members } & \multicolumn{7}{|c|}{ Year and Number of Livestock } \\
\cline { 2 - 8 } & 2006 & 2007 & 2008 & 2009 & 2010 & 2011 & 2012 \\
\hline Mukhtar & 112 & 136 & 143 & 63 & 71 & 81 & 89 \\
\hline Lentho & 154 & 162 & 156 & 55 & 67 & 74 & 81 \\
\hline Lao & 72 & 80 & 75 & 33 & 27 & 23 & 26 \\
\hline Aslam & 47 & 54 & 61 & 12 & 19 & 17 & 22 \\
\hline Jumma & 84 & 92 & 95 & 67 & 70 & 76 & 84 \\
\hline Junaid & 70 & 75 & 80 & 56 & 66 & 75 & 82 \\
\hline Shafi & 134 & 141 & 130 & 84 & 88 & 96 & 103 \\
\hline Mushtaq & 52 & 61 & 64 & 44 & 51 & 54 & 62 \\
\hline Tapio & 87 & 89 & 85 & 65 & 69 & 74 & 72 \\
\hline Manabar & 180 & 168 & 170 & 112 & 120 & 126 & 140 \\
\hline Tafi & 36 & 42 & 40 & 22 & 25 & 28 \\
\hline Mayio & 72 & 70 & 75 & 44 & 48 & 51 & 50 \\
\hline Source: Field Work (PirkiMarg pasture) Valley of Kashmir (2011) & & & 5 \\
\hline
\end{tabular}




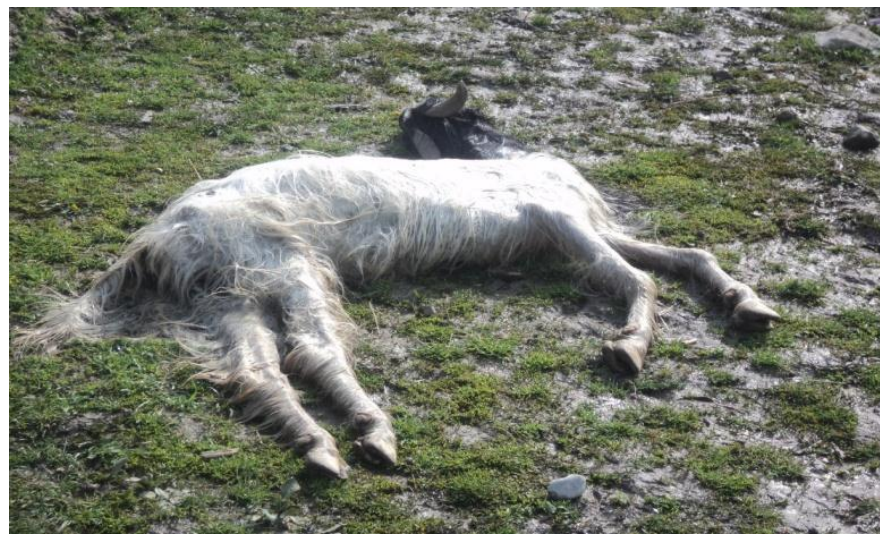

Dead animal during the Unseasonal Snowfall (Peer Ki Marg Summer Pasture, Shopian Dist., Kashmir Valley) But their way of life is under ever-increasing threat from loss of grazing land, worsening drought and government attempts to resettle them. Thousands of animals perished and more than 1 million people across Jammu and Kashmir are affected.

The availability of pasture was better in the past and the productivity of livestock was higher when we had better pasture,' according to Riaz, a Bakarwal shepherd. 'We get less rain now and when we get no rain at all things rapidly get worse as animals lose weight.

\section{Drying up of the water resources in the Winter Pastures}

According to the villagers in the Kha Village of Rajouri District (winter area) there were 7 water sources (springs) in and around the village.

Dried up Water Sources During the last 15 years

\begin{tabular}{|l|l|c|}
\hline \multicolumn{1}{|c|}{ S.No. } & \multicolumn{1}{|c|}{ Name of the water source } & Current status \\
\hline 1 & Salanpani & Dried up \\
\hline 2 & Kimganadho & Dried up \\
\hline 3 & Kathulgabawli & Dried up \\
\hline 4 & Banavalibawli & Dried up \\
\hline 5 & Sheeravalibawli & Dried up \\
\hline 6 & Meerunadho & Dried up \\
\hline 7 & Thikriyanalibaan & Dried up \\
\hline Source: Field Work,(2011) & & \\
\hline
\end{tabular}

All of these have dried up in recent times resulting in the reduction of drinking water for the livestock and humans. This has led to a decrease in the livestock production and early movement towards the summer pastures. The village has seen considerable decrease in the water levels across all the water sources.

\section{Decline in the Quality of Grasslands}

According to the elder members of the community, there is a decline in the quality of the grasslands from the last few years due to droughts. Frequency of the droughts has been increased from the last few years which force the community members to migrate from one pasture to another in search of grass to graze their animals.

100 percent nomadic Gujjars and Bakarwals respondents responded that they have problem with the forest department officials and to their rules. According to Gujjars and Bakarwals most of them are landless, shelter less and deserves dwelling rights on forest lands which they are using as traditional inhabitants since centuries together. To give these benefits to scheduled tribes, all the states of India except Jammu and Kashmir have implemented the Forest Rights Act 2006. Because of this they are subjected to the restrictions imposed by the forest department and are often made victims of harassment. Nomads of the study area have to pay grazing tax of varying amount for their cattle heads. Usually, barren lands are earmarked for grazing with ambiguous boundaries. If by chance, their livestock is spotted in other than grazing areas, the cattle are seized by the forest guards and they are heavily penalized. Some time false cases are booked and to get rid of the problem they pay huge bribe in cash and kinds. Bribing is common in the study area.

All nomadic Gujjars and Bakarwals informed that it is very difficult for them to sell their products on cash basis. In marketing place they are the victims of the village and town middlemen who run shops on a barter 
system. Whatever they produce it went to these shopkeepers and in return they supply to them inferior quality goods such as salt, clothes etc at high prices. Because of the limited transport facilities their exposure is restricted with such types of persons. Therefore, they never get their due for their best quality ghee, milk etc.

The pastoral economy of Gujjars and Bakarwals is dependent upon the availability and utilization of natural pastures. These pastures are markedly seasonal in their occurrence. As summer approaches, the pastures in the lower reaches dry up, but those in the upper reaches begin to thaw. As a result a sizeable number of Gujjars and Bakarwals move back and forth from the lower Himalayan region to pastures in the upper Himalayan ranges 79 percent respondents replied about quality of fodder and its shortage in their traditional meadows. They are not satisfied with their pastures land and because of this milk yield of the buffalo and the economy of Gujjars and Bakarwals are affected but still they continue their transhumant adaptive activities in these areas. They are dependent on their buffalo herds and would like to take them to good pastures. But depletion of resources in itself can be due to over utilization. And we know that over utilization means a direct consequence of rising human and animal population. These pastures are depleted due to over grazing and the cattle cannot get grass of adequate quantity and quality to satisfy their need. Besides, no care is taken to plant the good quality grasses either by the forest department or by the graziers concerned, nor any attention is paid to make good the losses due to over grazing i.e. receding etc. which should be a permanent and regular feature of pasture development programme.Most of the Gujjars and Bakarwals lead nomadic and semi- nomadic life. Their migratory mode of life also stands in the way of getting regular education. However government has opened number of mobile schools for them which move to high altitude and comes down to plains with the movement of Gujjars and Bakarwals. While conducting the survey 88 households from showed their concern over education of their wards. According to them, a number of nomadic schools are officially roaming with us but in reality they are not functional. Nonetheless, due to lack of effective supervision and control by the educational authorities over the field staff working in such remote and far flung areas, regularity and punctuality on the part of staff employed in such mobile schools is rare even though they belong to their community and areas.

\begin{tabular}{|l|c|}
\hline \multicolumn{2}{|c|}{ Other Problem faced by Gujjar and Bakarwals in the Study Area } \\
\hline \multicolumn{1}{|c|}{ Problems Faced } & Respondents \\
\hline Forest Department & 100 \\
\hline Good quality fodder & 80 \\
\hline Accommodation & 90 \\
\hline Militancy & 100 \\
\hline Nature & 100 \\
\hline Education of Children & 88 \\
\hline Medical facilities & 100 \\
\hline Marketing & 100 \\
\hline Drinking water and electricity & 100 \\
\hline Source: Field Work (2011) & \\
\hline
\end{tabular}

All households mentioned about the non availability of medical facilities in the higher reaches. Gujjars who were once known for their strong and attractive physique are now suffering with many ailments.

90 percent of the respondents replied that on the way and in the pasture lands they faced accommodation problems to live in. Although in the higher reaches they have constructed their Kothas but due to heavy snow and without any maintenance in the winter season they are not in a liveable position when they reached there. Drinking water and Electricity is another problem faced by them in the meadows. It is expressed by 90 percent of the respondents. Neither have they had pure drinking water facility nor electricity connection. The drinking water is inadequate for them and for livestock and they are required to fetch it from distant places.

Almost 100 percent of them feel that they are not safe in hands of natural calamities. They faced number of natural problems like rain, snowfall, heavy storm, hailstorms and landslides which cause not only loss of their near and dear but loss of their livestock also. In June, 2009 the unprecedented snowfall, which lashed the whole of Kashmir valley and parts of Jammu, took a heavy toll of life and property. As many as 300 people are killed and many are still reported missing. According to reports about 25,000 cattle perished besides destroying hundred of houses, mostly hutments of migratory population.Data further reveals that 100 household of Gujjars and Bakarwals expressed problem of militancy always haunting them. Sometimes Gujjars in J\&K are forced by the militants to become their guide. Also, they demand sheep and goats and other materials from them. And if Gujjars and Bakarwals object, they are either beaten up or killed.

\section{Fodder Shortage}

The pastoral economy of Gujjars and Bakarwals is dependent upon the availability and utilization of natural pastures. These pastures are markedly seasonal in their occurrence. As summer approaches, the pastures 
in the lower reaches dry up, but those in the upper reaches begin to thaw. But due to forced delay, they have to wait. Till then, they cannot feed their animal with freely available grasses. If they succeed to get scanty grass the cattle cannot get grass of adequate quantity and quality to satisfy their need. So they purchase grass from the local zamindars at their whimsical rates and get exploited.

\section{Animal Husbandry more Expensive}

After militancy, their livestock economy is purely becoming uneconomical for them. To run their bovine economy, they have to spend for everything. Due to this, the cost of production increases as compare to the prices of their milk and milk products. As result, they are unable to spend their money on other things which is very necessary for their survival.

\section{Recommendations}

A number of recommendations which were collected during the field work are as follows:

- Nomadic family should be settled down at the earliest possible. Shelter, safe drinking water and alternative livelihood to each and every family is strongly recommended.

- School education should be provided to the Gujjars and Bakarwals, separate schools for the girls should be provided. Mobile schools should be upgraded.

- Water and Electricity to every village inhabited by the Gujjars and Bakarwals.

- Arrangement for marketing of milk and milk products with the idea to strengthen their economic conditions.

- Ration card to every Gujjarsand Bakarwalfamily and ensure that they get the benefit of PDS.

- Promotion of Gujjars and Bakarwal veterinary health service.

- Development of grazing land with the help of forest department and cooperative societies.

- Make government schemes accessible to them and empower them for the same.

\section{References}

[1]. Rahi, Javaid, Chairman of the tribal cultural foundation of the Gujjars and Bakarwals. [2]. Chechi, Mukhtar, Bakarwal Shepherd, Aehrbal, Anantang -Kashmir.

[3]. The Hindu, $18^{\text {th }}$ July, 2010 http://www.thehindu.com/news/national/article441878.ece

[4]. Riaz, ABakarwal Shepherd, Afkataodh Summer Pasture, Shopian, Kashmir. 